\title{
Study on the Water in Lignite by DSC
}

\author{
You $\mathrm{Li}^{1}$, Shouyu Zhang ${ }^{1}$, Menghao Zhao ${ }^{1}$, Qing Mao ${ }^{1}$, Yunlong Yao ${ }^{1}$ and Jingning Yand \\ ${ }^{1}$ School of Energy and Power Engineering, University of Shanghai for Science and Technology, Shanghai, China \\ Corresponding Email: zhangsy-guo@163.com
}

\begin{abstract}
As pointed out in several previous works, new drying technologies must be developed to ensure lignite remained competitive. In order to design and test them, it was needed to have a better understanding of the characters of water in lignite. Using differential scanning calorimetry (DSC), three types of the water storing in the lignite were determined from congelation character. The contents of the free water and bound water were experimentally measured from their heats of congelation, respectively. The results shows that the congelation temperature and the freezing heat per weight unit of the bound water vary in different types of lignite. It is deduced that the bound water in lignite can reflect the character of lignite. Besides, the total water content of free water and bound water is less than that measured by fully drying at $105^{\circ} \mathrm{C}$. Therefore, it is deduced that there is a kind of water not frozen in the lignite, possibly because its molecular cluster is too small.
\end{abstract}

Keywords. Lignite, moisture, drying, differential scanning calorimetry

\section{Introduction}

The high moisture content of lignite in Eastern Inner Mongolia region reduces the efficiency of combustion, since in conventional processes part of the heat of combustion of the coal is wasted in removing this associated water. Therefore, the amount of carbon dioxide produced per MWh is higher for lignite than bituminous coal. New drying/dewatering technologies must be developed to ensure brown coal remains competitive [1], and in order to design and test them, it is necessary to have a better understanding of the fundamental physical and chemical characteristics of coal structure, particularly in relation to the forms of water in lignite.

Low temperature high resolution Differential Scanning Calorimetry (DSC) is a powerful tool for investigating water and solution behavior in porous materials [2]. It has been used for distinguishing the types of water in coal $[1,3,4,5]$. When the temperature is changed, phase transitions occur, and the energy (enthalpy) released during this process can be accurately measured. Since the slope of the DSC curve, the freezing heat per weight unit, is easy to obtain, the weight of the water that undergoes a phase change can be calculated [6]. Norinaga et al. [3] observed two exothermic peaks when cooling wet coal samples at $8^{\circ} \mathrm{C} / \mathrm{min}$ which were attributed to free or bulk water (large peak at $-15^{\circ} \mathrm{C}$ ) and to bound water (small peak at $-47^{\circ} \mathrm{C}$ ).

In this work, DSC was applied to characterize water in two kinds of lignite. The contents of different types of water in lignite were obtained.

\section{Material and methods}

Raw Samples. Two kinds of lignite, Datang-five-rooms (DT) lignite and Xilingol (XLGL) lignite, from China's Eastern Inner Mongolia region were chosen as the samples, whose datum of proximate and ultimate analyses were listed in table1, obtained by Institute of Coal Chemistry, Chinese Academy of Sciences.

Drying. The raw samples were smashed, and the lignite granules in size between $2 \mathrm{~mm}$ and $3 \mathrm{~mm}$ were selected. A portion of the samples were dried at $40^{\circ} \mathrm{C}$ for different time; the other part of the samples was dried at $40^{\circ} \mathrm{C}$ to constant mass and then at $105^{\circ} \mathrm{C}$ for different time. The drying samples were numbered and sealed for the follow-up analysis. The water content of the lignite was measured by heating at $105^{\circ} \mathrm{C}$ to constant mass, and the loss of mass as result of heating was taken as the water content.

Table 1. Proximate and ultimate analysis and calorific value of samples.

\begin{tabular}{|c|c|c|c|c|c|c|c|c|c|c|c|}
\hline \multirow{2}{*}{ Samples } & \multicolumn{4}{|c|}{ Proximate analysis [\%] } & \multicolumn{4}{c|}{ Ultimate analysis [\%] } & $Q_{\text {net,v,ad }}$ \\
\cline { 2 - 10 } & $M_{\mathrm{ad}}$ & $A_{\mathrm{ad}}$ & $V_{\mathrm{ad}}$ & $F C_{\mathrm{ad}}$ & & $C_{\mathrm{ad}}$ & $H_{\mathrm{ad}}$ & $O_{\mathrm{ad}}$ & $N_{\mathrm{ad}}$ & $S_{\mathrm{t}, \mathrm{ad}}$ & $\left.\mathrm{MJ}^{-1}\right]$ \\
\hline DT & 5.56 & 22.56 & 31.12 & 40.76 & 53.46 & 3.22 & 13.76 & 0.89 & 0.56 & 15.50 \\
\hline XLGL & 19.44 & 15.48 & 31.13 & 33.95 & 47.71 & 1.94 & 14.26 & 0.85 & 0.33 & 10.93 \\
\hline
\end{tabular}


Cooling in DSC Analyzer. DSC analysis was performed on Netzsch DSC200 analyzer with liquid nitrogen refrigeration accessories. The drying samples were milled and then sieved to less than $0.2 \mathrm{~mm}$. Approximately $5 \mathrm{mg}$ of coal sample was placed into the crucible each time. The crucible was cooled down from 15 to $-150^{\circ} \mathrm{C}$ with a rate of $8^{\circ} \mathrm{C} / \mathrm{min}$, using nitrogen as carrier gas at a constant flow rate of $80 \mathrm{ml} / \mathrm{min}$. The thermogram was recorded during the cooling process.

\section{Results and discussion}

Types of Freezable Water. The DSC curves of four representative samples were selected to compare with the curve of pure water. The curves in Fig.1 indicated the heat changing of samples in the cooling process, and the peaks indicated the exothermic process.

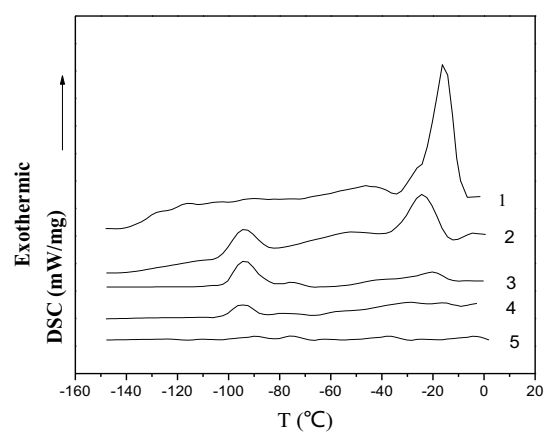

a - DT

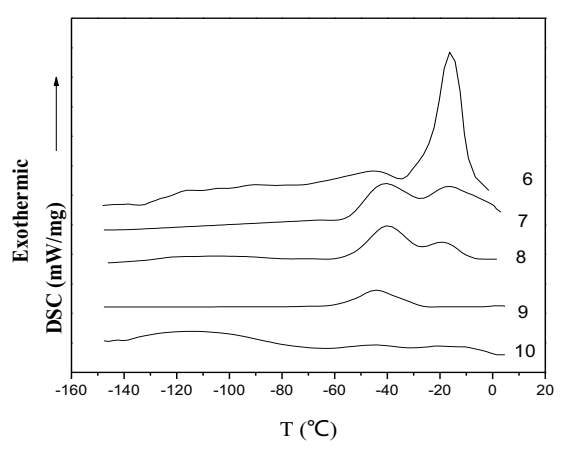

b - XLGL

1 and 6 - pure water; 2 and 7- raw lignite; 3 and 8 - lignite dried at $40^{\circ} \mathrm{C}$ for $30 \mathrm{~min}$; 4 and 9 - lignite dried at $105^{\circ} \mathrm{C}$ for $20 \mathrm{~min} ; 5$ and 10 - lignite fully dried at $105^{\circ} \mathrm{C}$.

Fig. 1. DSC thermogram of lignite.

The DSC curves for the samples and the pure water under cooling were shown in Figure 1. The peaks appearing in the thermograms were the result of exothermic processes. These peaks were attributed to the freezing of the water absorbed in the coal because such peaks were never observed for the samples fully dried at $105^{\circ} \mathrm{C}$.

According to the contrast between curve 1 and 2, the big peak of raw DT lignite was similar to that exhibited by pure water, which was attributed to free water. In addition, as previously noted by Norinaga et al [3], a small peak at $-90^{\circ} \mathrm{C}$ was also shown by the curve of raw DT lignite in the Fig. 1a, which was defined as bound water according to the study of Nakamura et al [7]. Contrasting curve 2, 3 and 4, it was shown that the bound water did not start to be separated out until the free water fully evaporated. The phenomenon indicated that it was harder for bound water in lignite to be separated out than bulk water in lignite because of the coal-water reaction [5].

Fig. 1b showed similar phenomenon to Fig. 1a. Differently, the peak of bound water in XLGL lignite appearing at $-45^{\circ} \mathrm{C}$, which indicated that the bound water in XLGL lignite was easier to separate out than that in DT lignite. Therefore, the coal-water interaction in XLGL lignite was weaker than that in DT lignite. To sum up, the bound water in lignite could represent the characteristics of water rather than the free water in lignite.

Content Measurement of Different Kinds of Water. The relationship between the freezing heat and moisture contents of the samples was shown in the Figure 2. As it was showed in Figure 2a, the decrease in freezing heat per unit reduction of water mass was $330.1 \mathrm{~J} / \mathrm{g}$ of water in the range of 0.335 to $0.213 \mathrm{~g} / \mathrm{g}$ coal (db.), and it was in agreement with the congelation heat of pure water into ice, $334 \mathrm{~J} / \mathrm{g}$. It was proved again that the peaks at $-15^{\circ} \mathrm{C}$ was ascribed to water which had little interaction with the coal.

In Figure $2 \mathrm{a}$, for water contents ranging from 0.213 to $0.128 \mathrm{~g} / \mathrm{g}$ coal (db.), $\Delta \mathrm{H}$ decreased with a slope of $188 \mathrm{~J} / \mathrm{g}$ of water, which was considered as bound water [7]. As it was analyzed previously, the congelation heat of capillary-condensed water was generally less than that of free water [8]. The content of the two kinds of water could be figured out based on enthalpy released and the slope during the cooling process. 

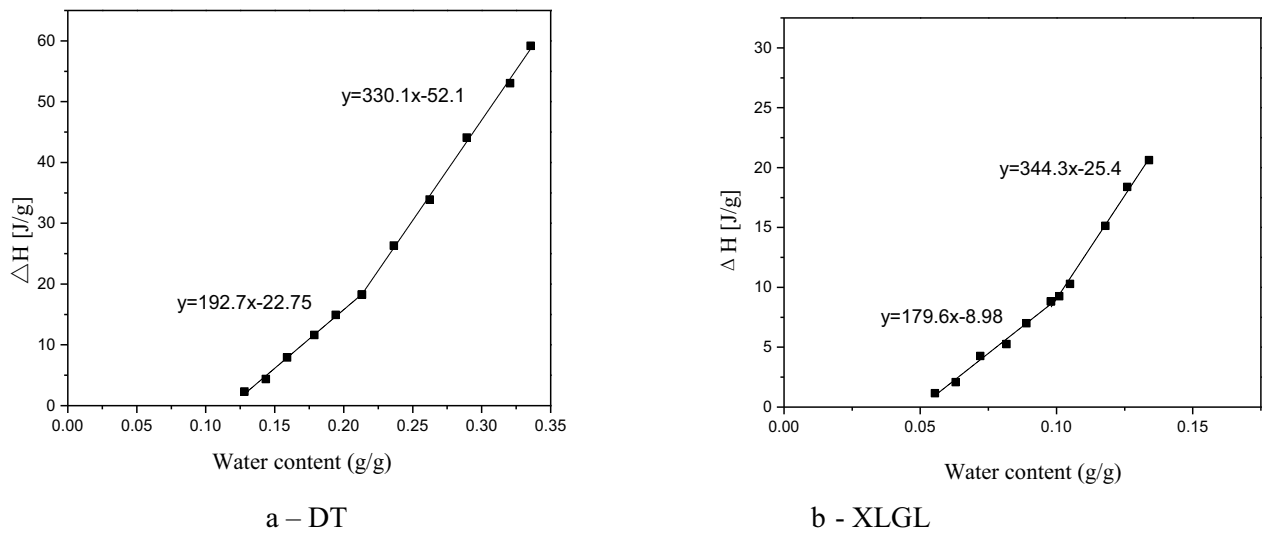

Fig. 2. Heat released from lignite by freezing.

However, the total water content of free water and bound water was less than that obtained by fully drying at $105^{\circ} \mathrm{C}$. Therefore, there was likely to be a kind of water that was not freezable in lignite, namely, non-freezable water. Sheng et al [9] reported that water became non-freezable when the molecular cluster was too small. The content of the non-freezable water could be calculated by difference. The similar phenomenon for XLGL lignite was shown in Fig.2b. In summary, the three kinds of moisture in two kinds of lignite were listed in Table 2, respectively.

\begin{tabular}{|c|c|c|c|c|c|c|}
\hline \multicolumn{9}{|c|}{ Table 2. Results of DSC analysis. } \\
\hline \multirow{3}{*}{ Sample } & \multicolumn{2}{|c|}{$\begin{array}{c}\text { Peak temperature } \\
{\left[{ }^{\circ} \mathrm{C}\right]}\end{array}$} & \multirow{2}{*}{ Congelation enthalpy[J/g] } & \multicolumn{3}{c|}{ Kinds of moisture [g/g coal (db.) $]$} \\
\cline { 2 - 5 } & Peak 1 & Peak 2 & & $\begin{array}{c}\text { Free } \\
\text { water }\end{array}$ & $\begin{array}{c}\text { Bound } \\
\text { water }\end{array}$ & $\begin{array}{c}\text { Non-freezable } \\
\text { water }\end{array}$ \\
\hline \multirow{2}{*}{ DT } & -15 & -90 & $330.1,192.7$ & $\begin{array}{c}0.1223 \\
(37 \%)\end{array}$ & $\begin{array}{c}0.0952 \\
(28 \%)\end{array}$ & $\begin{array}{c}0.118 \\
(35 \%)\end{array}$ \\
\hline XLGL & -15 & -42 & $344.3,179.6$ & $\begin{array}{c}0.036 \\
(27 \%)\end{array}$ & $\begin{array}{c}0.048 \\
(36 \%)\end{array}$ & $\begin{array}{c}0.05 \\
(37 \%)\end{array}$ \\
\hline
\end{tabular}

\section{Conclusions}

(1) There were two kinds of water contained in lignite, free water and bound water, which could be coagulated. In the DSC test environment, the coagulation temperature of free water was $-15^{\circ} \mathrm{C}$, and that of bound water in DT lignite was $-90^{\circ} \mathrm{C}$ solidification, and that of bound water in XLGL lignite was $-45^{\circ} \mathrm{C}$. In addition to the water that could be condensed, lignite contained non-freezable water, which could be calculated by difference.

(2) The content of water in DT lignite included $0.14 \mathrm{~g} / \mathrm{g}$ coal (db.) as free water, $0.083 \mathrm{~g} / \mathrm{g}$ coal $(\mathrm{db}$.) as bound water and $0.127 \mathrm{~g} / \mathrm{g}$ coal $(\mathrm{db}$.) as non-freezable water; The content of water in XLGL lignite included $0.036 \mathrm{~g} / \mathrm{g}$ coal (db.) as free water, $0.048 \mathrm{~g} / \mathrm{g}$ coal $(\mathrm{db}$.) as bound water and $0.05 \mathrm{~g} / \mathrm{g}$ coal $(\mathrm{db}$.) as non-freezable water.

\section{Acknowledgements}

This research was supported by the National Science \& Technology Pillar Program during the Twelfth Five-year Plan Period (Grant No.2012BAA04B01).

\section{References}

1. D.J. Allardice, L.M Clemow, G. Favas, W.R. Jackson, M. Marshall and R. Sakurovs: The Characterisation of Different Forms of Water in Low Rank Coals and Some Hydrothermally Dried Products. Fuel Vol. 82 (2003), p. 661-667.

2. L.G. Homshaw: High Resolution Heat Flow DSC: Application to Study of Phase Transitions, and Pore Size Distribution in Saturated Porous Materials. Journal of Thermal Analysis Vol. 19 (1980), p. 215-234.

3. N. Koyo, K. Haruo, J. Hayashi and T. Chiba: Classification of Water Sorbed in Coal on the Basis of Conflation Characteristics. Energy \& Fuels. Vol. 12 (1998), p. 574-579. 
4. F. Yi, C. A.L. Chaffee, M. Marshall and W.R. Jackson: Lignite-water Interactions Studied by Phase Transition-Differential Scanning Calorimetry. Fuel. Vol.84 (2005), p. 1557-1562.

5. T. Arash, J. Yu., H. Su, Y. Han, J. Lucas, H. Zheng and T. Wall: A Differential Scanning Calorimetric (DSC) Study on the Characteristics and Behavior of Water in Low-rank Coals. Fuel vol.135 (2014), p. 243-252.

6. G. Zhou, Q. Huang, B. Yu, F. Wang, Y. Chi and J. Yan: Study on the critical particle size of high moisture low rank coals drying in fluid-ized-bed reactor via low temperature Differential Scanning Calorimetry (DSC). Meitan Xuebao/Journal of the China Coal Society Vol.40 (2015), p. 185-189.

7. K. Nakamura, T. Hatakeyama and H. Hatakeyama: Relationship between hydrogen bonding and bound water in poly hydroxystyrene derivatives. Polymer Vol. 24 (1983), p. 871-876.

8. S.C. Mraw and D.F. O'Rourke: Water in Coal Pores: The Enthalpy of Fusion Reflects Pore Size Distribution. Journal of Colloid and Interface Science. Vol.89 (1982), p. 268-271.

9. P. Sheng, R.W. Cohen and J.R. Schrieffer: Melting Transition of Small Molecular Clusters. Journal of Physics C: Solid State Physics. Vol.14 (1981), p. 565-569. 